\title{
Laboratory Study on the Fatigue Resistance of Asphaltic Concrete Containing Titanium Dioxide
}

\author{
Rosnawati Buhari ${ }^{1, *}$, Mohd Ezree Abdullah ${ }^{1}$, Mohd Khairul Ahmad ${ }^{2}$, Saiful Azhar \\ Tajudin ${ }^{1}$ and Siti Khatijah Abu Bakar ${ }^{1}$ \\ ${ }^{1}$ Faculty of Civil and Environmental Engineering, Universiti Tun Hussein Onn Malaysia, 83000, \\ Batu Pahat, Johor Malaysia \\ ${ }^{2}$ MINT-SRC, Universiti Tun Hussein Onn Malaysia, 86400, Parit Raja, BatuPahat Johor, Malaysia
}

\begin{abstract}
This study aims to evaluate the fatigue performance of modified asphalt mixture using Indirect Tensile Fatigue Test. Titanium Dioxide $\left(\mathrm{TiO}_{2}\right)$ powder in a form of rutile was used for producing asphalt concrete with lower mixing and compaction temperature compared to conventional hot mix asphalt without reducing its physical and mechanical also resistance to fatigue. The characteristic of the asphalt and modified asphalt was evaluated using penetration test, softening test and rotational viscosity test. Titanium dioxide of $2 \%, 4 \%, 6 \%, 8 \%$ and $10 \%$ by weight of asphalt has been incorporated into unaged $80 / 100$ asphalt mix in order to improvise its performance and to fulfill the objectives of this experimental study. As a result, $\mathrm{TiO}_{2}$ as an additive is potential to decrease the penetration and increasing the softening point of the asphalt. In terms of fatigue performance testing, addition $\mathrm{TiO}_{2}$ additive does help in improving the fatigue properties as it shows greater result than the control asphalt. In conclusion, $\mathrm{TiO}_{2}$ is great in improving fatigue properties.
\end{abstract}

\section{Introduction}

Warm Mix Asphalt (WMA) is one of the technologies that has been gaining attention in recent years, is used to reduce the heating, mixing and compaction temperature of the asphalt mixture, improving the working condition at site, reduced time of compaction in site and minimizes the negative effects on the environment. These technologies can reduce the production temperature of the Hot Mix Asphalt (HMA) by $16^{\circ} \mathrm{C}$ to over $55^{\circ} \mathrm{C}$ [1]. It was first applied in Europe in the year 1997, followed by United States in 2002 [2]. Exposure of WMA mixture is relatively new in Malaysia, however, it is becoming a mainstay in construction and pavement industry. To date, long term performances of WMA mixture are still being reviewed and there is no pavement failures or concerns have been observed. WMA is an alternative for hot mix asphalt (HMA) and is produced at a temperature ranging from $120^{\circ} \mathrm{C}$ to $140^{\circ} \mathrm{C}$, which is $10^{\circ} \mathrm{C}$ to $40^{\circ} \mathrm{C}$ lower than that of HMA [3]. This environmental friendly technology has claimed to contribute to

* Corresponding author: rosna@uthm.edu.my 
lower emission of fumes, less energy usage, better working environment and longer hauling time without compromising the performance of the pavement. In order to attain lower asphalt production and compaction temperature whilst maintaining its feasible viscosity, additives are needed to be incorporated in the mixture. According to Kilas et.al, three types of commonly found WMA technology in the worldwide are foam asphalt, organic additives and chemical additives [3]. These additives will help in lowering the viscosity of asphalt during the production process of WMA, which is a crucial factor in obtaining high workability of the asphalt. For example, Abdullah et. al was conducted a study on performance of WMA mixture using nanoclay modified asphalt binder called Nano Clay Modified Binder (NCMB) in terms of moisture susceptibility, rutting and fatigue potential [4]. The prepared the WMA samples using mixing temperature $135^{\circ} \mathrm{C}$, $125^{\circ} \mathrm{C}$ and $115^{\circ} \mathrm{C}$ and less $10^{\circ} \mathrm{C}$ for compaction temperature. As a result, the fatigue life was decreased as it is decreasing in mixing and compaction temperature. Also, Moatasim et al. conduct on study WMA with modified asphalt using HDPE as an additive, the objective of the study is to evaluate the performances of the asphalt concrete mixtures that using modified asphalt 80/100 with HDPE [5]. From the result, the performance of the concrete mixtures improve when used 5\% of HDPE by weight in asphalt blend. Then, Yu Kuang et al., did a researched with two main objective, first is to evaluate on behaviour of Evotherm-J1 and M1 as additive in compaction technology and second objective is to study the effect of Evotherm-J1 and M1as additive in moisture anti strip [6]. The study carried by Diefenderfer et al. (2008), using sasobit as an additive in asphalt with two different mixtures in the study.

In this study, chemical additive known as titanium dioxide $\left(\mathrm{TiO}_{2}\right)$ was used to evaluate the properties and performance of the asphalt pavement. The objectives of this study are to; (i) evaluate the physical properties of asphalt modified with Titanium dioxide based on Malaysia Standard Specification and Superpave binder specification and (ii) evaluate and compare the fatigue characteristics of asphalt modified with $\mathrm{TiO}_{2}$ at warm mix asphalt compacted temperature with conventional hot mix asphalt.

\section{Methodology}

\subsection{Materials}

There are several sizes of sieve typically used for Superpave mix design which includes sieve size $37.5 \mathrm{~mm}, 19 \mathrm{~mm}, 12.5 \mathrm{~mm}, 9.5 \mathrm{~mm}, 4.75 \mathrm{~mm}, 2.36 \mathrm{~mm}, 1.18 \mathrm{~mm}, 0.600 \mathrm{~mm}$, $0.300 \mathrm{~mm}, 0.150 \mathrm{~mm}$ and $0.075 \mathrm{~mm}$. The gradation size was determinate follow the Superpave gradation limit. The $\mathrm{TiO}_{2}$ used are in form of rutile particles size ranges from 40 $\mathrm{nm}$ to $70 \mathrm{~nm}$ as shown in Fig. 1 and the binder used are asphalt penetration grade 80-100. The selection of rutile form are based on the purity of titanium dioxide substance in its composition and higher surface area as the smaller sizes of particle, the surface area are higher.

\subsection{Sample preparation}

The modified asphalt was prepared using asphalt of penetration grade 80/100 as base asphalt and several percentage of $\mathrm{TiO}_{2}$ in powder form. It is started by placing the $500 \mathrm{~g}$ of base asphalt in an aluminum can and then placed in the oven at $155^{\circ} \mathrm{C}$ for approximately half an hour. It was then put on top of a hot plate and continuously observes to ensure that the asphalt stayed constant at $155^{\circ} \mathrm{C}$. Next, a specified percentage of $\mathrm{TiO}_{2}$ by weight of asphalt are gradually added into the asphalt as the high shear 
asphalt mixer is rotating at $5200 \mathrm{rpm}$ for duration of 30 minutes. The blending parameter used in this task are follows the procedure that came out with the homogeneous mixture in previous study [7].

To evaluate the fatigue characteristic of the mixture, the Optimum asphalt Content $(\mathrm{OBC})$ was determined in the first place. The aggregate gradation with nominal size 9.5 $\mathrm{mm}$ was used. The maximum content of the aggregate is $4.75 \mathrm{~mm}$ sieve size and the filler content is $2 \%$ from total weight of $1200 \mathrm{~g}$. A HMA mixture without $\mathrm{TiO}_{2}$ content was prepared using mixing and compaction temperature that are $165^{\circ} \mathrm{C}$ and $155^{\circ} \mathrm{C}$ respectively. It was denoted as control mixture and WMA mixture that containing $\mathrm{TiO}_{2}$ were prepared by using mixing and compaction temperature of $135^{\circ} \mathrm{C}$ and $125^{\circ} \mathrm{C}$.

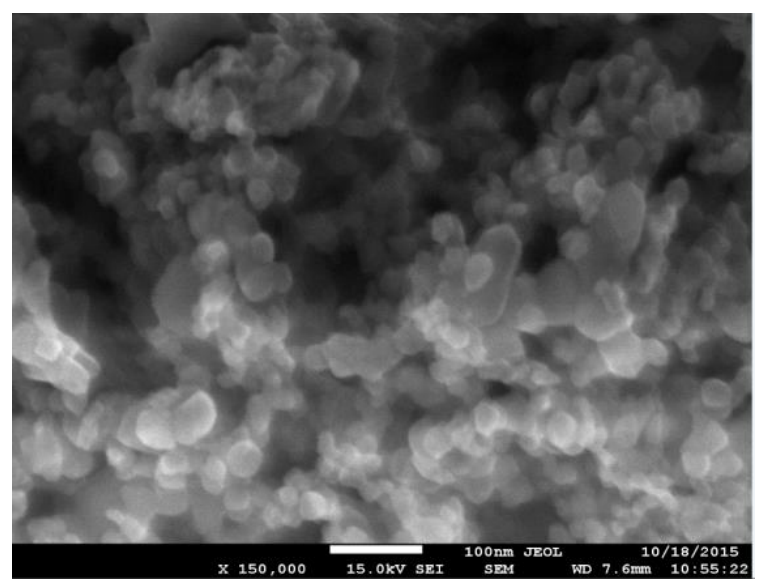

Fig. 1. Morphology of the $\mathrm{TiO}_{2}$.

\subsection{Laboratory testing}

A laboratory testing was conducted based on American Society for Testing and Material (ASTM), American Association of State Highway and Transportation (AASHTO), Asphalt Institute Superpave Asphalt Binder Test Methods and Asphalt Institute Superpave Mix Design (SP-2). A penetration test was conducted followed ASTM D5 while softening point test following ASTM D36 [8-9]. Brookfield Viscometer was used in rotational viscosity (RV) test to measure the flowing resistance of asphalt materials [10]. The Superpave ${ }^{\mathrm{TM}}$ specification requires that the maximum viscosity of asphalt binder is no greater than $3 \mathrm{~Pa} . \mathrm{s}$ at $135^{\circ} \mathrm{C}$ for the convenience of storage and pumping in construction period [11]. Sieve analysis was conducted to find the aggregates gradation that followed the Superpave aggregates gradation limit [11]. The determination of the OBC was following the trial asphalt content based on $9.5 \mathrm{~mm}$ aggregates size with $5 \%, 5.5 \%, 6.0 \%$ and $6.5 \%$ trial asphalt content. After OBC was determined, mixtures sample for Indirect Tensile fatigue test was conducted. Fatigue cracking is one of prominent pavement distress in tropical countries after several years of construction due to weathering and repeated numbers of traffic loads. In laboratory, for asphalt mixture the Indirect Tensile Fatigue test (ITFT) was conducted using Universal Testing Machine (UTM) to evaluate the fatigue performance of modified asphalt mixture with $\mathrm{TiO}_{2}$ powders. Before testing is conducted, sample and related testing accessories were conditioned at $20^{\circ} \mathrm{C}$ for a minimum 4 hours in the provided environmental chamber to reach a uniform temperature throughout the specimen. After that, testing is run at the 
same temperature and the specimen was exposed to a repeated compressive load 45 equal to $600 \mathrm{kPa}$ with a haversine load signal through the vertical diametral plane followed by a loading time of $0.1 \mathrm{~s}$ and rest period of $0.4 \mathrm{~s}$. The pattern of loading applied to the specimen is relatively uniform tensile stress perpendicular to the direction of the applied load. After certain period, the testing is terminated and the total number of cycles was recorded.

\section{Results and discussions}

\subsection{Physical and flow behaviour}

Softening point test and Penetration test were performed to determine the physical properties of unaged virgin and modified binder. Table 1 shows that the penetration value is gradually getting lower as more additive is added into the binder. This shows that addition of additive does help in improving the hardness of the binder, which is a desired factor in modified binder property. Softening Point test measured the temperature where asphalt material starts to change to liquid state [12]. Higher softening point indicates stiffer asphalt and lower temperature susceptibility at high temperature, which is more preferred in hot climates. As seen in Table 3, the softening point value started to increase for modified binder added with $2 \% \mathrm{TiO}_{2}$ until $8 \% \mathrm{TiO}_{2}$. It can be concluded that the penetration value decreases as higher percentage of additive was added to the binder. This indicates that proper amount of $\mathrm{TiO}_{2}$ added can help in improving the stiffness of the asphalt.

Table 1. Results of Softening Point and Penetration Test.

\begin{tabular}{|c|c|c|}
\hline Sample $\left(\% \mathrm{TiO}_{2}\right)$ & Softening point $\left({ }^{\circ} \mathrm{C}\right)$ & Penetration test $(\mathrm{mm})$ \\
\hline 0 & 46.4 & 99.8 \\
\hline 2 & 47.7 & 96.1 \\
\hline 4 & 49.3 & 94.2 \\
\hline 6 & 50.4 & 89.4 \\
\hline 8 & 51.1 & 83.2 \\
\hline 10 & 51.9 & 79.6 \\
\hline
\end{tabular}

Fig. 2 shows viscosity test results. Conventional asphalt is known to have a higher mixing and compaction temperature compared to modified asphalt. As shown in the table, enhancement the reading by increasing the percentage of additive while the result become decreasing when the temperature raised until $180^{\circ} \mathrm{C}$. As a conclusion, this additive can increasing the viscosity of asphalt binder.

The analysis continue with plotting graph in Fig. 3 for determination of recommendation of compaction and mixture temperature value. According to Superpave Asphalt Binder Test Method (SP-1), references line for compaction range and mixing range which are 0.25 to 0.31 for compaction and 0.15 to 0.19 for mixing. It was found that the minimum compaction temperature value for warm mix asphalt has larges value than control, while the minimum mixing temperature value is better than control value, this can be expressed the modified binder is using less energy and fuel than control binder for preparation of binder. 


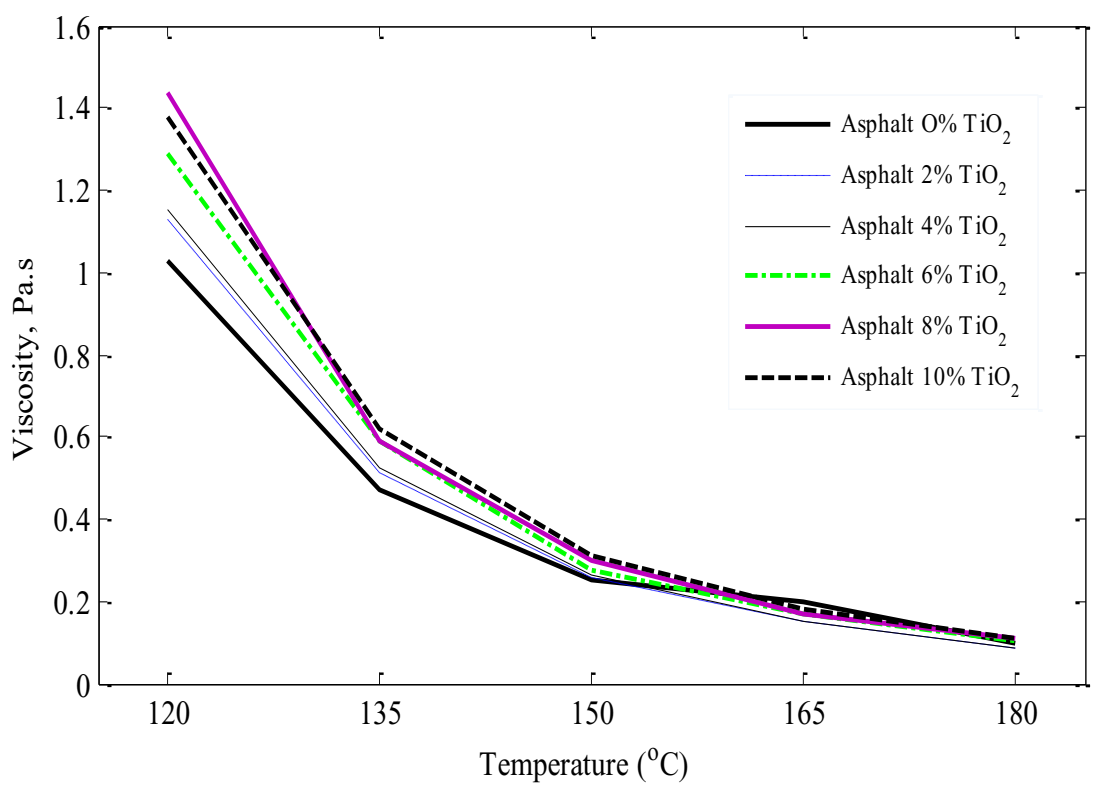

Fig. 2 Rotational viscosity of original asphalt 80/100 and Modified asphalt with $\mathrm{TiO}_{2}$.

\subsection{Resistance to fatigue}

Fatigue is a major distresses normally occurred in asphalt pavement. Fatigue occurs at low to intermediate temperature while rutting occurs at higher temperature. The initiation and propagation of cracking generally relates to the magnitude of dissipated energy produced by external loading. In this study, results of ITFT according to the mixing and compaction temperature for the mixture are shown in Table 2 and the trend of fatigue resistance of the mixture is illustrate in Fig. 3. The trend for mixtures compacted at $125^{\circ} \mathrm{C}$ is showing an increasing pattern as the percentage of $\mathrm{TiO}_{2}$ increased. This could indicate that proper amount of $\mathrm{TiO}_{2}$ addition will help to improve the reaction between the binder and the aggregates, which eventually increases the strength of the mixture as a whole and completly increased the performance of the mixture againt fatigue failure.

Table 2. Fatigue life cycle

\begin{tabular}{|c|c|c|c|}
\hline Sample $\left(\% \mathrm{TiO}_{2}\right)$ & $\begin{array}{c}\text { Mixing } \\
\text { Temperature, } \\
\left({ }^{\circ} \mathrm{C}\right)\end{array}$ & $\begin{array}{c}\text { Compaction } \\
\text { Temperature, } \\
\left({ }^{\circ} \mathrm{C}\right)\end{array}$ & Fatigue life cycles \\
\hline 0 & 165 & 155 & 11416 \\
\hline 2 & 135 & 125 & 12051 \\
\hline 4 & 135 & 125 & 12578 \\
\hline 6 & 135 & 125 & 13145 \\
\hline 8 & 135 & 125 & 13463 \\
\hline 10 & 135 & 125 & 13866 \\
\hline
\end{tabular}




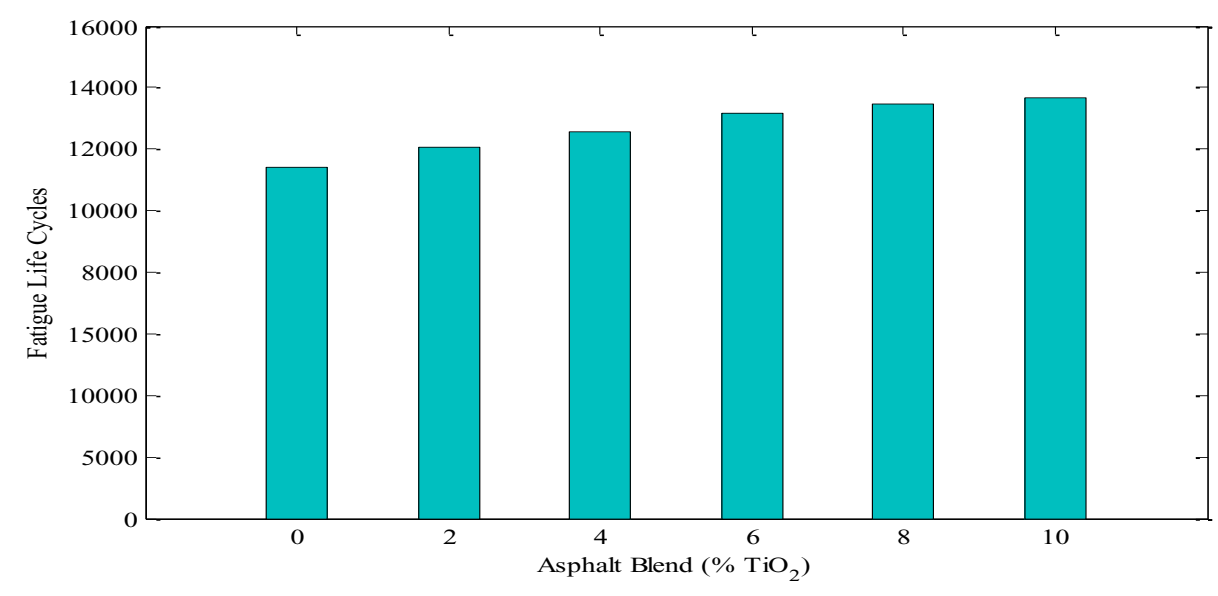

Fig. 3. Number of cycles of modified asphalt with $\mathrm{TiO}_{2}$.

\section{Conclusions}

In this study, a $\mathrm{TiO}_{2}$ in a powder form of rutile particles of $2 \%, 4 \%, 6 \%, 8 \%$ and $10 \%$ were added to the base binder to investigate for the effectiveness of the additives in improving the properties of the binder. Based on the results presented, the following findings can be deduced with respect to the applications:

- The addition of $\mathrm{TiO}_{2}$ has significantly improved the penetration and softening point of the asphalt. This demonstrated the improvement of stiffness of the binder and also better temperature susceptibility.

- Addition of $\mathrm{TiO}_{2}$ has the potential in reducing the mixing temperature of the mixture.

- In terms of fatigue cracking performance of mixture, addition of modified $\mathrm{TiO}_{2}$ does aid in controlling the effectiveness of mixture towards fatigue resistance.

In conclusion, higher percentage of $\mathrm{TiO}_{2}$ in form of rutile particles is a good substance to be used as additive in Warm Mix Asphalt as it improved the physical and fatigue performance characteristics of the binder. It is also reducing the temperature of the mixing.

The authors wish to thank the Universiti Tun Hussein Onn Malaysia. This study was funding by Ministry of Higher Learning Malaysia under FRGS Grant (1458).

\section{References}

1. D’Angelo, J., Harm, E., Bartoszek, J., Baumgardner, G., Corrigan, M., Cowsert, J., Harman, T., Jamshidi, M., Jones, W., Newcomb, D., Prowell, B., Sines, R., Yeaton, B. Federal Highway Administration (FHWA), Alexandria, FHWA Report 08-007 (2008)

2. Kumar, M., Vaitkus, A., \& Paliukait, M.. $10^{\text {th }}$ International Conference of Modern Building Materials, Structures and Techniques, Lithuana, (2010)

3. Kilas, M., Vaitkus, A., \& Paliukait, M, Warm Mix Asphalts Research, Analysis and Evaluation. $10^{\text {th }}$ International Conference, (2010)

4. Abdullah, M.E., Zamhari, K.A., Buhari, R., Bakar, S. K. A., Kamaruddin, N. H. M.,Nayan, N., Hainin, M. R., Hassan, N. A., Hassan, S. A., Yusoff, N. I. M., Journal Technology (Sciences \& Engineering) 71 (2014)

5. Moatasim, A., Cheng, P.F., Al-Hadidy, Constr Build Mater 25 (2011) 
6. Al-Mansob, R. A., Ismail, A., Alduri, A. N., Azhari, C. H., Karim, M. R., \& Yusoff, N. I. Constr Build Mater 63 (2014)

7. Buhari. R, Chong, A.L., Abdullah M. E., Abu Bakar S. K., Mohd Kamarudin N. H., Shamsudin M.K., Ahmad M.K., Puteh S., Jurnal Teknologi 5 (2016)

8. ASTM D36, Annual Book Of American Society For Testing And Materials (ASTM) Standards, West Conshohocken, United States (2005)

9. ASTM D5, Annual Book of American Society For Testing And Materials (ASTM) Standards, West Conshohocken, United States (2005b)

10. AASHTO T315, Determining The Rheological Properties Of Asphalt Binder Using A Dynamic Shear Rheometer (DSR), (2010)

11. Asphalt Institute, Superpave Mix Design, Superpave Series No.2 (SP-2)(2001)

12. Asphalt Institute, Superpave Performance Graded Asphalt Binder Specifications and Testing, Series No. 1 (SP-1) (2003) 